position paper, controlling antimicrobial use is not enough to combat resistance. ${ }^{6}$ Hospitals also must focus on appropriateness of use, and respond to data from a monitoring system. Of hospitals we surveyed, only $70 \%$ had CPGs that addressed such issues, and less than one half of the hospitals had a system to measure compliance with consultations on initial antimicrobial choice. Furthermore, despite recent evidence that selected restrictions decrease antimicrobial resistance, only $40 \%$ of hospitals restricted any antimicrobials. ${ }^{7,8}$ Therefore, it is evident that, in most hospitals surveyed, practices to improve antimicrobial use existed. However, these effor ts should be considered a first step in approaching more comprehensive programs such as those described in the SHEA-IDSA position paper.

One limitation of this study is that we have no information on enforcement of, or changes in, the reported practices. However, this survey provides an overview of some of the more commonly reported methods to improve antimicrobial use. Our data demonstrate the variety of programs currently used and may reflect the current lack of data demonstrating that any one program is more effective than others.

\section{REFERENCES}

1. Fridkin SK, Steward CD, Edwards JR, Pryor ER, McGowan JE Jr, Archibald LK, et al. Surveillance of antimicrobial use and antimicrobial resistance in United States hospitals: project ICARE phase 2. Project
Intensive Care Antimicrobial Resistance Epidemiology (ICARE) hospitals. Clin Infect Dis 1999;29:245-252.

2. McGowan JE Jr, Tenover FC. Control of antimicrobial resistance in the health care system. Infect Dis Clin North Am 1997;11:297-311.

3. Hamilton $C D$, Drew R, Hayward S, Kure J, Janning S. Improving clinician adherence to vancomycin-use guidelines: results of a pharmacistbased strategy at an academic medical center. Clin Infect Dis 1997;25:425. Abstract 381.

4. Bamberger DM, Dahl SL. Impact of voluntary vs enforced compliance of third-generation cephalosporin use in a teaching hospital. Arch Intern Med 1992;152:554-557.

5. Goldmann DA, Weinstein RA, Wenzel RP, Tablan OC, Duma RI, Gaynes $\mathrm{RP}$, et al. Strategies to prevent and control the emergence and spread of antimicrobial-resistant microorganisms in hospitals. JAMA 1996;275:234-240.

6. Shlaes DM, Gerding DN, John JF Jr, Craig WA, Bornstein DL, Duncan RA, et al. Society for Healthcare Epidemiology of America and Infectious Diseases Society of America Joint Committee on the Prevention of Antimicrobial Resistance: guidelines for the prevention of antimicrobial resistance in hospitals. Infect Control Hosp Epidemiol 1997;18:275-291.

7. Frank MO, Batteiger BE, Sorensen SJ, Hartstein AI, Carr JA, McComb JS, et al. Decrease in expenditures and selected nosocomial infections following implementation of an antimicrobial-prescribing improvement program. Clinical Performance and Quality Health Care 1997;5:180-188.

8. White AC Jr, Atmar RL, Wilson J, Cate TR, Stager CE, Greenberg SB. Effects of requiring prior authorization for selected antimicrobials: expenditures, susceptibilities, and clinical outcomes. Clin Infect Dis 1997;25:230-239.

9. Evans RS, Pestotnik SL, Classen DC, Clemmer TP, Weaver LK, Orme JR $\mathrm{J} r$, et al. A computer assisted management program for antibiotics and other antiinfective agents. N Engl J Med 1998;338:232-238.

10. Rifenburg RP, Paladino JA, Hanson SC, Tuttle JA, Schentag JJ. Benchmark analysis of strategies hospitals use to control antimicrobial expenditures. Am J Health Syst Pharm 1996;53:2054-2062.

\title{
Nosocomial Infections in a Neurosurgery ICU
}

\section{Gina Pugliese, RN, MS Martin S. Favero, $\mathrm{PhD}$}

Dettenkofer and coinvestigators from the Institute of Environmental Medicine and Hospital Epidemiology, University Hospital Freiburg, Germany, conducted a study to identify overall and site-specific nosocomial infection (NI) rates in patients receiving neurosurgical intensive care therapy. A prospective study was started in February 1997 in the eight-bed neurosurgical ICU of the University Hospital of Freiburg, Germany. Case records were reviewed twice per week, all microbiology reports were reviewed, and ward staff were consulted. NIs were defined according to $\mathrm{CDC}$ criteria and were categorized into specific infection sites. Within 20 months, 545 patients with a total of
5,117 patient-days were investigated (mean length of stay, 9.4 days). One hundred thirteen NIs were identified in 90 patients ( 72 patients with 1,13 with 2 , and 5 with 3 infections, respectively). A moderate to high overall incidence (20.7/100 patients) and a moderate incidence density (22.1/1,000 patient-days) of NI in the neurosurgical ICU could be documented; these figures are well within the range of published data.

Site-specific incidence rates and incidence densities were as follows: 1 bloodstream infection (BSI) $/ 100$ patients (0.9 central line-associated BSIs $/ 1,000$ central line-days), 9 pneumonias $/ 100$ patients (15.1 ventilator-associated pneumonias/ 1,000 ventilator-days), and 7.3 urinary tract infections (UTIs) $/ 100$ patients (8.5 urinary catheter-associated
UTIs/1,000 urinary catheter-days). Additionally, 1.1 cases of meningitis, 0.7 brain abscesses/ventriculitis, and 1.7 other infections (surgical-site infection, bronchitis, catheter-related local infection, and diarrhea) were documented per 100 patients, respectively. Of isolated pathogens, $14.6 \%$ were Escherichia coli; $10.2 \%$, enterococci; $9.6 \%, S$ aureus; $6.4 \%$, coagulasenegative staphylococci; $6.4 \%$, Klebsiella species; 5\%, Enterobacter species; and 5\%, Pseudomonas species. In 11 cases of NI, no pathogen could be isolated.

FROM: Dettenkofer M, Ebner W, Hans FJ, Forster D, Babikir R, Zentner J, et al. Nosocomial infections in a neurosurgery intensive care unit. Acta Neurochir (Wien) 1999;141:13031308. 